\title{
Characterization of CD44-mediated hyaluronan binding by renal tubular epithelial cells
}

\author{
Beat Oertli ${ }^{1}$, Xiaohong Fan $^{1}$ and Rudolf P. Wüthrich ${ }^{1,2}$ \\ Physiological Institute ${ }^{1}$, University of Zürich-Irchel, and Division of Nephrology ${ }^{2}$, University Hospital, Zürich, Switzerland
}

\begin{abstract}
Background. CD44 is the main receptor for the extracellular polysaccharide hyaluronan (HA). We have recently shown that CD44 is strongly induced on renal tubular epithelial cells (TEC) in autoimmune renal injury and that HA accumulates in the renal interstitium (Kidney Int 1996; 50: 156-163 and Nephrol Dial Transplant 1997; 12: 1344-1353). The functional significance of enhanced tubular CD44 expression and its interaction with HA are not known. The purpose of the present study was to characterize renal tubular CD44 expression and CD44-mediated HA binding in vitro and to investigate the growth modulating effects in response to HA binding by TEC.
\end{abstract}

Methods. RT-PCR analysis, flow cytometry, confocal microscopy and Western blotting were used to examine cell surface and soluble CD44 expression by cultured TEC, using SV40-transformed mouse cortical tubular (MCT) cells. HA binding characteristics were examined by flow cytometry and effects of HA on TEC cell growth by $\left[{ }^{3} \mathrm{H}\right]$ thymidine incorporation.

Results. By RT-PCR analysis MCT cells expressed predominantly the standard form of CD44 mRNA, whereas the expression of variant forms was very weak. Confocal microscopy showed that CD44 was expressed basolaterally and apically on MCT cells with strong staining on microvilli. Shedding of CD44 from MCT cells could be induced with crosslinking of antiCD44 mAbs or with PMA stimulation. MCT cells constitutively bound HA and this binding could be modulated with anti-CD44 mAbs. Soluble and plate-bound HA markedly inhibited MCT cell growth.

Conclusions. CD44 is a regulated HA receptor on MCT cells which can be shed into the cellular environment. Upon binding of HA, CD44 functions as a growth inhibitory cell surface protein in MCT cells. We speculate that the interaction of CD44 with HA may have important regulatory effects on cell proliferation in tubulointerstitial renal diseases.

Correspondence and offprint requests to: Rudolf $\mathrm{P}$. Wüthrich, Division of Nephrology, University Hospital, Rämistrasse 100, CH-8091 Zürich, Switzerland.
Key words: CD44; cell growth; hyaluronan; tubular epithelial cells

\section{Introduction}

The leukocyte antigen CD44 is a widely distributed cell surface proteoglycan which functions as a receptor for the matrix constituent hyaluronan (HA) [1]. Through its expression on non-haematopoietic parenchymal cells CD44 is involved in various biological processes, including cell migration, metastasis and inflammation [2].

We have recently shown that CD44 is induced on proximal tubular epithelium in immune-mediated renal injury, including murine lupus nephritis (MRL-Fas ${ }^{l p r}$ model ) [3] and tubulointerstitial disease (CBA/CaH$k d k d$ model) [4]. We also found that HA markedly accumulates in the renal interstitium in MRL-Fas ${ }^{l p r}$ mice (unpublished observation) and $\mathrm{CBA} / \mathrm{CaH}-k d k d$ mice [4], particularly in areas where tubular epithelial CD44 is upregulated. The functional significance of CD44 expression on TEC, its mechanism of interaction with $\mathrm{HA}$ and its role in immune-mediated tubular injury are presently not known. We have speculated, however, that tubular CD44 could interact with its ligand in vivo and modulate tubular cell function in response to this ligand interaction [3].

Since CD44 is expressed by cultured renal tubular epithelial cells (TEC) [3] we have used a clonal TEC line to characterize the pattern of CD44 expression and its interaction with $\mathrm{HA}$ in vitro and to gain insight into the functional significance of CD44 expression on TEC. Here we show that a defined TEC line expresses high levels of the standard but not the variant forms of CD44, both apically and basolaterally. Furthermore, shedding of CD44 from TEC can be induced. CD44 binds HA constitutively and the binding capacity for HA can be modulated with mAbs targeting CD44. We also demonstrate that HA inhibits the growth of TEC through its ligand CD44. Thus, upon interaction with HA renal tubular CD44 functions as a growth inhibiting molecule. We speculate that the interaction of CD44 with HA could 
play a role in the regeneration and differentiation of injured TEC in vivo in various renal diseases with a tubulointerstitial component.

\section{Materials and methods}

\section{Reagents}

Tissue culture reagents were obtained from Life Technologies (Gaithersburg, MD) and chemicals from Sigma (St Louis, MO). Dr J. Lesley (San Diego, CA) provided us with the IRAWB14.4 hybridoma [5], producing an activating anti-CD44 monoclonal antibody (mAb) and with FITC-labelled HA. Purified sodium hyaluronate with a molecular weight of approx. $4-6 \times 10^{5}$ was obtained from Fluka (Buchs, Switzerland). Table 1 lists the target antigen, properties and source of the mAbs used in this study. The hybridomas for the mAbs IM7.8.1 [6], KM114 [7] and KM81 [7] were obtained from the American Type Culture Collection (ATCC, Rockville, MD). Hybridoma culture supernatants were purified using protein G-Sepharose CL-6B columns. KM114 was biotinylated according to a standard protocol.

\section{Cell lines and cell cultures}

An SV40-transformed mouse cortical tubular (MCT) cell line was used to study the expression and functional role of CD44 [8]. MCT cells were grown in tissue culture dishes in DMEM media supplemented with 10\% FBS, 10 mM HEPES, $100 \mathrm{U} / \mathrm{ml}$ penicillin and $100 \mu \mathrm{g} / \mathrm{ml}$ streptomycin.

\section{RNA extraction, RT-PCR and Southern blotting for CD44}

Total RNA from cultured MCT cells was extracted as described [9]. Total RNA from murine kidney was isolated using lysis in guanidinium isothiocyanate and ultracentrifugation at 35000 r.p.m. through a $\mathrm{CsCl}_{2}$ gradient overnight [10]. The RNA was analysed for CD44 expression by RT-PCR as described [3] using a kit (Perkin-Elmer, Branchburg, NJ). For optimal detection of CD44 variant forms we used primers located in the CD44 sequence directly flanking the variant exon insertion site [11]. The upstream primer 5'-ACC CCA GAA GGC TAC ATT TTG C-3' and the downstream primer 5'-CTC ATA GGA CCA GAA GTT GTG G-3' were used to detect the presence of such variant forms. RT-PCR products were then resolved on $2 \%$ agarose gels.

To ensure specificity of the amplified fragments we performed Southern blot analysis and hybridization with a

Table 1. Characteristics of anti-CD44 monoclonal antibodies

\begin{tabular}{lllll}
\hline Clone & Target & Properties & Source & Reference \\
\hline IM7.8.1 & CD44 & Neutral & ATCC & {$[6]$} \\
KM81 & CD44 & HA binding blocker & ATCC & {$[7]$} \\
KM114 & CD44 & $\begin{array}{c}\text { Partial HA binding } \\
\text { blocker }\end{array}$ & ATCC & {$[7]$} \\
IRAWB14.4 & CD44 & $\begin{array}{c}\text { Induces HA binding } \\
\text { J. Lesley }\end{array}$ & {$[5]$} \\
\hline
\end{tabular}

cDNA probe encoding for CD44 as described [3]. Blots were washed under stringent conditions (final wash in $0.2 \times \mathrm{SSC}$, $1 \%$ SDS, $60^{\circ} \mathrm{C}$ ). Following hybridization the blots were exposed to Kodak X-OMAT AR film.

\section{Flow cytometry}

Flow cytometry was performed as described [3]. Briefly, cultured MCT cells were grown to confluence and were then detached with $5 \mathrm{mM}$ EDTA in HBSS. Cells were washed once with $\mathrm{Ca}^{2+}$ - and $\mathrm{Mg}^{2+}$-free HBSS and were resuspended in PBS containing 5\% FCS. Cells were then incubated with the primary $\mathrm{mAb}$ for $1 \mathrm{~h}$ at $4^{\circ} \mathrm{C}$, were washed twice with $\mathrm{PBS} / 5 \% \mathrm{FCS}$ and were then incubated with FITC-conjugated goat anti-rat $\mathrm{IgG}$ for $1 \mathrm{~h}$ at $4^{\circ} \mathrm{C}$. After repeated washing with $\mathrm{PBS} / 5 \% \mathrm{FCS}$, cells were fixed with $2 \%$ paraformaldehyde. Measurements were performed on an Epics ${ }^{\circledR}$ Coulter flow cytometer.

\section{Confocal microscopy}

The cellular distribution of CD44 on cultured MCT cells was determined by confocal microscopy. MCT cells were grown in DMEM $/ 10 \%$ FBS medium on coverslips coated with type II collagen until subconfluent. Cells were then fixed in $4 \%$ paraformaldehyde and were blocked with $20 \mathrm{mM}$ glycine and subsequently with $3 \%$ milk powder (w/v). For detection of intracellular CD44 cells were then permeabilized with $0.1 \%$ saponin (v/v). Rat anti-mouse mAb IM7.8.1 $(5 \mu \mathrm{g} / \mathrm{ml})$ in $3 \%$ milk powder was used to detect CD44. FITC-conjugated affinity-purified goat anti-rat IgG (Sigma, St Louis, MO) was used at 1:40 as secondary antibody.

CD44 expression was then assessed with a confocal laser scanning microscope (LSM 410, Zeiss, Germany) at magnifications of $630 \times$ using the $488 \mathrm{~nm}$ line spectrum of a He-Na laser source. Optical sections were obtained at focal steps of 28 or $56 \mathrm{~nm}$. Stacks of $51 x-y$ sections were used to generate extended focus projections, $x-z$ sections and 3-D reconstructions, using the Imaris ${ }^{\circledR}$ software (Bitplane, Zürich, Switzerland).

\section{Shedding of CD44 from MCT cells}

Shedding in response to crosslinking of anti-CD44 mAb was assessed by flow cytometry. Confluent MCT cells were detached and resuspended in DMEM $/ 10 \% \mathrm{FBS}$ and were then incubated with $\mathrm{mAb}$ IM7.8.1 at $10 \mu \mathrm{g} / \mathrm{ml}$ and crosslinked using anti-rat $\mathrm{IgG}$ for $5 \mathrm{~h}$ at $37^{\circ} \mathrm{C}$. Adhesion and clumping of MCT cells was prevented by shaking the tubes every hour. For detection of remaining cell surface CD44, cells were then stained with biotinylated KM114 mAb, using a streptavidinR-phycoerythrin conjugate for detection (Sigma, St Louis, MO). Cells were then analysed by flow cytometry.

Soluble CD44 protein was also assayed in the supernatant of MCT cells by SDS-PAGE and Western blotting. Supernatants from control and from PMA-stimulated MCT $(20 \mu \mathrm{g} / \mathrm{ml})$ were size fractionated on a $10 \%$ SDS-PAGE under reducing and non-reducing conditions and blotted on to nitrocellulose. To detect soluble CD44 the membranes were then processed with a chemiluminescence detection system (Western-Star, Tropix, Bedford, MA). Membranes were blocked with casein and were incubated with the antiCD44 mAb IM7.8.1. After washing, blots were incubated with alkaline phosphatase-conjugated goat anti-rat IgG 
(1:5000). The 1,2-dioxetane substrate (CDP-Star) was then added to the blots according to the instructions provided from the manufacturer. Membranes were exposed briefly ( $30 \mathrm{~s}$ to $5 \mathrm{~min}$ ) to Kodak LS film and were then developed.

\section{HA binding to CD44 on MCT cells}

The HA binding capacity of MCT cells was assessed by flow cytometry. Confluent cells were detached and resuspended in $\mathrm{PBS} / 5 \% \mathrm{FCS}$ and incubated with HA-FITC at $1: 800$ for $1 \mathrm{~h}$ at $4{ }^{\circ} \mathrm{C}$. To control for non-specific binding cells were also incubated with FITC-labelled goat anti-rat IgG. The influence of anti-CD44 mAb on HA-binding was assessed by incubating cells with either purified $\mathrm{mAb}$ for $1 \mathrm{~h}$ at $4^{\circ} \mathrm{C}$ before staining with HA-FITC.

\section{Proliferation assays}

The influence of soluble HA on proliferation was assessed as follows: MCT cells were grown in 96-well plates (Nunc Intermed, Roskilde, DK) to confluence with DMEM $/ 10 \%$ FBS. Cells were then rested for $24 \mathrm{~h}$ in DMEM $/ 1 \%$ FBS. HA $(500-1000 \mu \mathrm{g} / \mathrm{ml})$ was then added and cells were incubated at $37^{\circ} \mathrm{C}$ for the indicated time. Proliferation was then assessed by $\left[{ }^{3} \mathrm{H}\right]$ thymidine incorporation, adding $1 \mu \mathrm{Ci} /$ well and harvesting the cells $18 \mathrm{~h}$ later with a Cambridge PHD cell harvester (Cambridge Technology, Cambridge, USA). $\left[{ }^{3} \mathrm{H}\right]$ thymidine incorporation was counted with a Kontron Betamatic V liquid scintillation counter.

The effect of plate-bound HA was investigated as follows: 96-well plates were coated with $\mathrm{HA}$ at $500 \mu \mathrm{g} / \mathrm{ml}$ (dissolved in PBS and adjusted to $\mathrm{pH} 8.5$ ) overnight at $4{ }^{\circ} \mathrm{C}$. Plates were then washed twice with PBS and blocked for $4 \mathrm{~h}$ with $1 \%$ (w/v) albumin. Confluent MCT cells were harvested by trypsinization and added at $1 \times 10^{4}$ cells/well, plates were then incubated in DMEM $/ 10 \% \mathrm{FBS}$ at $37^{\circ} \mathrm{C}$ for $48 \mathrm{~h}$. Proliferation was then assessed as mentioned above, using $\left[{ }^{3} \mathrm{H}\right]$ thymidine.

\section{Results}

\section{Characterization of CD44 expression by MCT cells}

RNA was isolated from confluent MCT cells to detect the presence of transcripts encoding for the standard (CD44s) and the alternatively spliced isoforms of CD44 (CD44v) by RT-PCR and Southern blotting. Figure 1A shows that mRNA for CD44s was readily detected in MCT cells. Variant forms (CD44v) could only be visualized after prolonged exposure of the blots (not shown). In comparison, RT-PCR fragments representing CD44v were readily detected in kidney RNA from $\mathrm{CBA} / \mathrm{CaH}-k d k d$ mice (positive control), but not in kidney RNA from MRL-Fas ${ }^{l p r}$ mice with lupus nephritis, as described previously [3,4].

Flow cytometry was then used to examine the cell surface expression of the CD44 protein by MCT cells. Figure 1B shows that MCT cells stained intensely with the anti-CD44 mAb KM114 (100\% of cells expressing CD44).

We then used confocal microscopy to examine more precisely the cellular location of CD44. MCT cells stained intensely for CD44, confirming the results
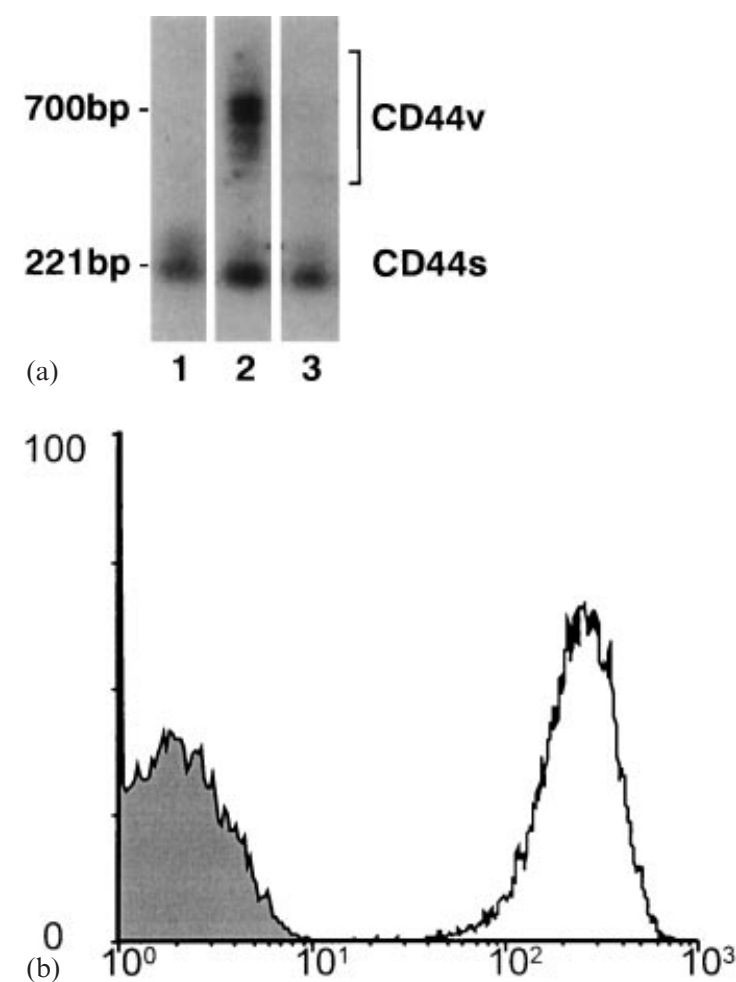

Fig. 1. (A) RT-PCR and Southern blot analysis of MCT-and kidneyderived total RNA for CD44s and CD44v isoforms. Primers flanking the extracellular insertion site for the variant exons were used to detect alternatively spliced transcripts. Lane 1: MCT cells express mainly standard CD44 (221 bp RT-PCR fragment). Lane 2 . Standard and additional variant forms are expressed in the kidney of a 6 month old $\mathrm{CBA} / \mathrm{CaH}-k d k d$ mouse with tubulointerstitial disease. Lane 3: CD44 is mainly expressed as the standard form (221 bp) in the kidney of a 4-month-old MRL-Fas ${ }^{\text {lpr }}$ mouse. (B) Flow cytometric analysis for CD44 cell surface expression by MCT cells, using biotinylated anti-CD44 mAb KM114. Shaded area represents cells stained with control $\mathrm{mAb}$, white area with antiCD44 mAb. Note that $100 \%$ of cells are strongly CD44-positive.

obtained by flow cytometry. Figure $2 \mathrm{~A}$ shows that apical microvilli were strongly positive for CD44. The apical expression was confirmed by examining $x-z$ (Figure 2B, bottom) and $y-z$ sections (Figure 2B, upper right) which showed membrane bound CD44 around the cell with no preference for apical, basal or lateral sides. Sections in the $x-y$ direction indicated that most of the CD44 protein was membrane bound in MCT cells (Figure 2C, thin arrow), but a cytoplasmic fraction could also be detected in permeabilized cells (Figure 2C, dotted arrow). With the confocal images we also obtained evidence for shedding of CD44 by MCT cells. Figure 2D (3D reconstruction) shows CD44 retraction traces (arrow) and shedded remnants of cell membranes which are also CD44 positive (dotted arrow).

\section{Shedding of CD44 by MCT cells}

To characterize further the shedding of CD44 by MCT cells we used flow cytometry after crosslinking 

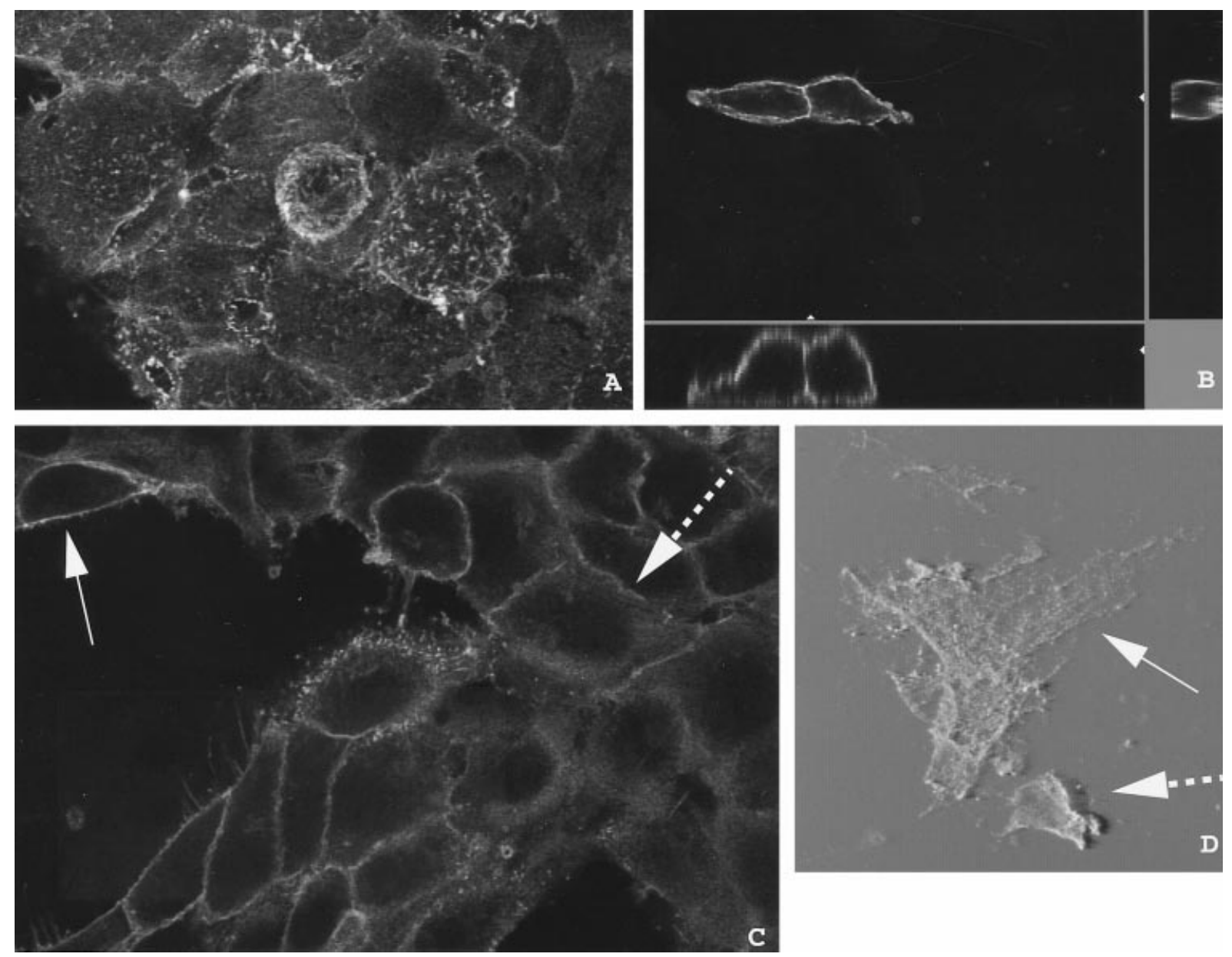

Fig. 2. Confocal microscopy of MCT cells stained for CD44. (A) Strong staining for CD44 on apical microvilli. (B) Cross-sections of two MCT cells. Upper left: $x-y$ section, upper right: $y-z$ section, bottom panel: $x-z$ section. MCT cells express CD44 apically and basolaterally. (C) MCT cells were permeabilized with $0.1 \%$ saponin to detect intracellular CD44. Dotted arrow points to a cell with diffuse intracellular staining sparing the nucleus and more accentuated membrane staining. Thin arrow shows strong rim staining for CD44. (D) 3-D reconstruction of area where cells have retracted (arrow), demonstrating shedded remnants of cell membrane which are CD44 positive (dotted arrow) and CD44 retraction traces.

CD44 with anti-CD44 mAbs. MCT cells were incubated with anti-CD44 mAb IM7.8.1 and bound $\mathrm{mAb}$ was crosslinked with anti-rat IgG. Figure $3 \mathrm{~A}$ demonstrates that CD44 staining with biotinylated KM114 was intense $(100 \%)$ in control cells (thick line). After crosslinking the mean fluorescence intensity decreased by $55 \%$ (thin line). Incubation of MCT cells with IM7.8.1 alone without crosslinking reduced the mean fluorescence intensity insignificantly (dotted line). Thus, crosslinking CD44 with IM7.8.1 and anti-rat IgG effectively decreased CD44 cell surface staining, suggesting shedding of CD44 by MCT cells via this mechanism.

To prove further that CD44 is shed by MCT cells we then performed SDS-PAGE and Western blotting to detect immunoreactive CD44 in the culture supernatant of MCT cells after stimulation with the phorbol ester PMA. Cells were grown to confluence and were then incubated with PMA for $48 \mathrm{~h}$. Figure $3 \mathrm{~B}$ shows that a protein around $80 \mathrm{kDa}$ could be detected in the PMA-stimulated supernatants but not in non- stimulated MCT cell supernatants, demonstrating PMA-induced shedding of CD44 by MCT cells.

\section{$H A$-binding capacity of MCT cells is modulated by $m A b$ against $C D 44$}

To determine whether cell surface CD44 functions as a HA receptor on MCT cells we examined the HA binding capacity using a FITC-labelled HA probe. Incubation with FITC-labelled HA for $1 \mathrm{~h}$ showed moderate HA binding by unstimulated MCT cells (Figure 4). To exclude non-specific binding for HA-FITC, MCT cells were incubated with unlabelled $\mathrm{HA}$ at 10 -fold excess before staining with HA-FITC. HA-FITC binding was completely abrogated by this procedure (data not shown).

As previously described, the anti-CD44 mAb KM81 inhibits the HA binding capacity in many cell types [7], whereas the activating anti-CD44 mAb IRAWB14.4 is able to induce or increase the HA binding capacity of lymphocytes $[5,12]$. To determine 


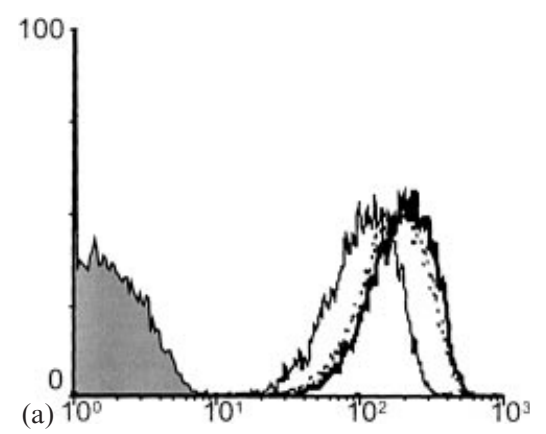

(a)

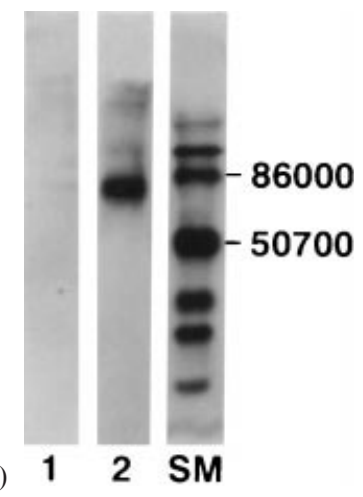

Fig. 3. (A) Shedding of CD44 is induced with crosslinking CD44. MCT cells were incubated with anti-CD44 mAb IM7.8.1 and antirat $\mathrm{IgG}$ for $5 \mathrm{~h}$ and stained with biotinylated KM114 for remaining CD44. Shaded area: control (staining with secondary reagent); thick black line: control cells stained with biotinylated KM114 alone; dotted line: staining with biotinylated KM114 after incubation with IM7.8.1 without crosslinking; thin black line: staining with biotinylated KM114 after IM7.8.1 incubation with crosslinking. The fluorescence shift to the left after crosslinking of CD44 indicates shedding of CD44. (B) Detection of soluble CD44 in the supernatant of MCT cells by Western blotting. MCT cells were stimulated with PMA for $48 \mathrm{~h}$ in DMEM/1\% FBS and the supernatant was harvested. Supernatants were run on a $10 \%$ SDS-PAGE gel using nonreducing conditions and blotted onto nitrocellulose. Soluble CD44 was detected using the IM7.8.1 mAb. Lane 1: control (48 h); lane 2: MCT cells stimulated with PMA for $48 \mathrm{~h}$; lane 3 : protein size marker (Da).

whether HA binding to CD44 on MCT cells could also be influenced by anti-CD $44 \mathrm{mAbs}$ we incubated cells with purified anti-CD44 mAbs before adding HA-FITC. Figure 4A shows that mAb KM81 inhibited HA binding dose-dependently, displaying complete HA binding inhibition at $50 \mu \mathrm{g} / \mathrm{ml}$. In contrast, IRAWB14.4 stimulated HA binding markedly at 10 and $50 \mu \mathrm{g} / \mathrm{ml}$ (Figure 4B). Thus, the modulation of HA binding capacity by anti-CD44 mAbs on MCT cells was similar to that described for lymphocytes.

\section{HA inhibits proliferation of MCT cells}

To gain insight into the functional consequences of HA binding to CD44 on MCT cells we examined the proliferation of these cells in the presence or absence of HA. We used both soluble HA and plate-bound HA. Figure $5 \mathrm{~A}$ shows that the addition of soluble HA at 500 or $1000 \mu \mathrm{g} / \mathrm{ml}$ to confluent MCT cells inhibited
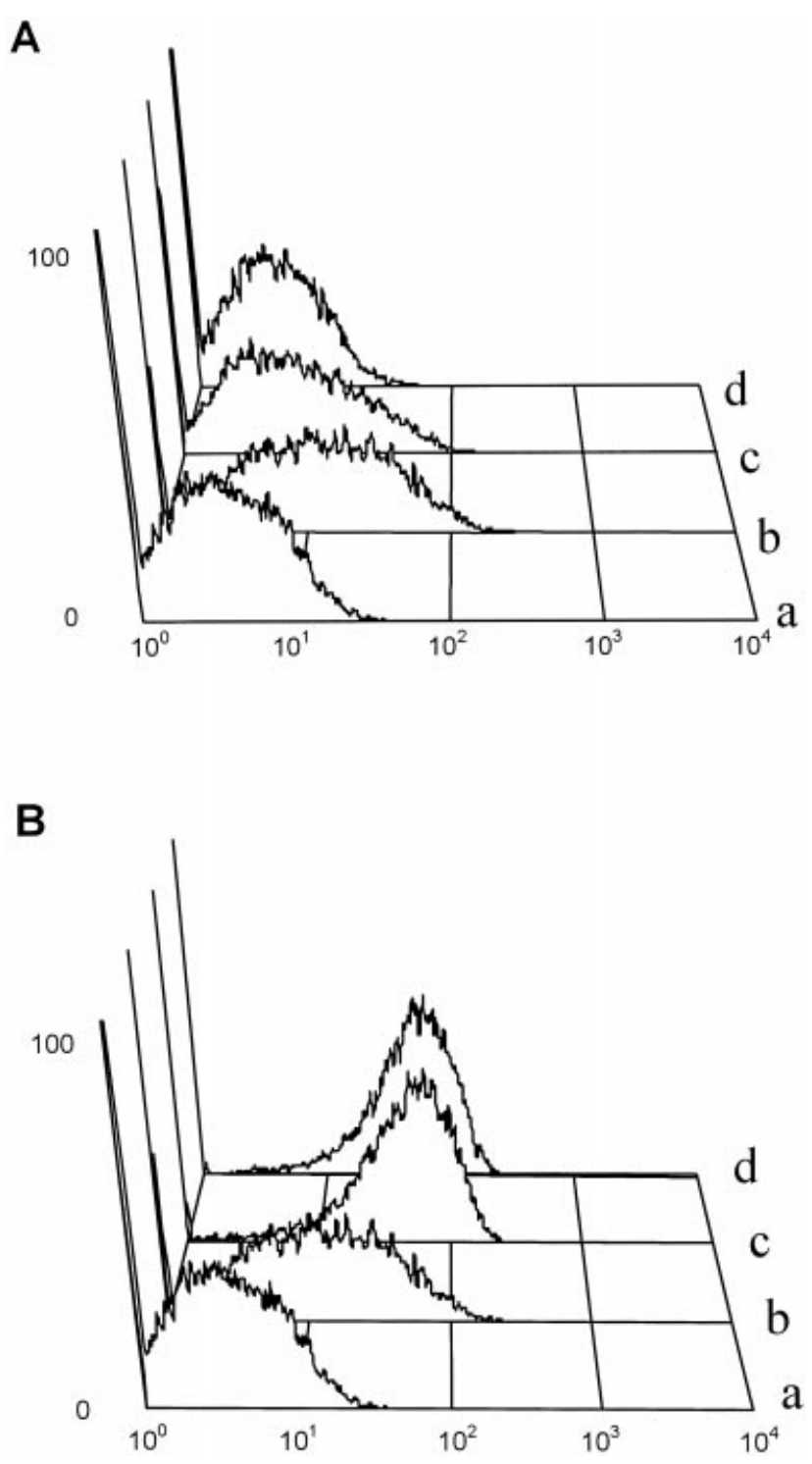

Fig. 4. Flow cytometric analysis for detection of HA binding to MCT cells. (A) The KM81 mAb inhibits HA binding on MCT cells. Cells were incubated with KM81 before incubation with FITClabeled HA. (a) control (FITC-labeled anti-rat IgG only); (b) HA-FITC only; (c) KM81 at $10 \mu \mathrm{g} / \mathrm{ml}$ followed by HA-FITC; (d) KM81 at $50 \mu \mathrm{g} / \mathrm{ml}$ followed by HA-FITC. (B) The IRAWB14.4 induces HA binding on MCT cells. Cells were incubated with IRAWB14.4 before incubation with FITC-labeled HA. (a) control; (b) HA-FITC only; (c) IRAWB 14.4 at $10 \mu \mathrm{g} / \mathrm{ml}$ followed by HA-FITC; (d) IRAWB14.4 at $50 \mu \mathrm{g} / \mathrm{ml}$ followed by HA-FITC.

DNA synthesis $\left(\left[{ }^{3} \mathrm{H}\right]\right.$ thymidine incorporation) markedly and in a dose-dependent manner. Furthermore Figure 5B shows that a significant inhibitory effect of HA could also be demonstrated when MCT cells were grown on plate-bound HA $(P<0.005, t$-test, five different experiments).

\section{Discussion}

CD44 is a versatile cell surface glycoprotein with numerous structural diversities and functional characteristics 
A

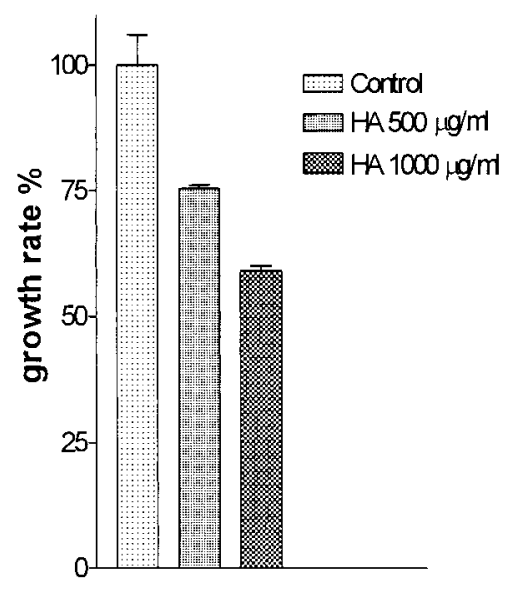

B

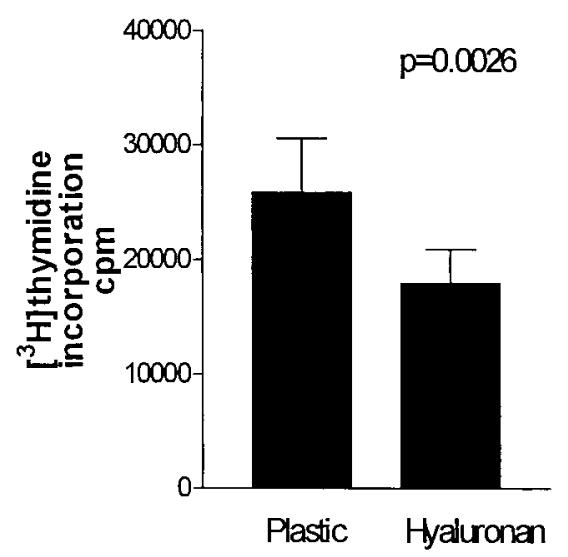

Fig. 5. Soluble and plate-bound HA inhibit the growth of MCT cells. Cells were grown in 96-well plates and proliferation was assessed by $\left[{ }^{3} \mathrm{H}\right]$ thymidine incorporation. (A) Soluble HA when added for $24 \mathrm{~h}$ to confluent MCT cells dose-dependently inhibited proliferation (triplicate data from one of three representative experiments). (B) MCT cells grown on HA-coated (500 $\mu \mathrm{g} / \mathrm{ml}) \mathrm{plates}$ display reduced proliferation (data are pooled from five different experiments, each individual experiment was done in triplicate, $P<0.005$ ).

$[2,13,14]$. CD44 is expressed by renal proximal tubules in immune-mediated renal injury but not in normal kidneys $[3,4,15,16]$. Because the in vivo role of enhanced tubular CD44 expression is not known we have examined a defined clonal TEC line (MCT cells) to characterize the expression pattern of CD44 and to examine the functional consequences of HA interaction with CD44 in vitro. Here we show that cultured TEC express CD44 abundantly on the cell surface. CD44 can also be shed from the cell surface and is found in the supernatant of cultured MCT cells. We also show that CD44 on MCT cells functions as a HA receptor whose capacity to bind its ligand can be modulated with anti-CD44 antibodies. Furthermore we found that the binding of HA to CD44 inhibits cell proliferation markedly.

We chose the clonal cell line MCT to study the interaction of HA and CD44 on renal tubular epithelial cells because of many advantages compared to other cell lines or primary culture tubular cells. MCT cells display high constitutive expression of CD44s which is stable and not influenced by culturing conditions, while culture of primary tubular epithelial cells leads to upregulation of CD44 during the culturing process (unpublished results). Diseased renal tubular cells ([27], our unpublished results) and MCT cells have an apical and basolateral distribution of CD44 while transfected MDCK cells express CD44 only on the basolateral side [28]. MCT cells therefore reflect more closely the in vivo situation. Also, renal tubular cell lines (e.g. C1 [29]) which need an extracellular matrix constituent to grow were not suitable for our experiments because the presence of collagen in the culture system could have influenced the results. Finally CD44 on MCT cells is not occupied by endogenous HA, thus allowing us to assess the interaction of $\mathrm{HA}$ and CD44 directly.
It is known that CD44 exists as a soluble molecule in addition to the cell surface form. Cleavage of CD44 from the cell surface by proteases or insertion of an additional alternatively spliced exon which introduces a premature stop codon (thereby creating a low molecular soluble CD44 isoform) have been implicated as possible mechanisms responsible for the shedding [17]. Our results demonstrate that MCT cells are capable of shedding CD44 after crosslinking or after stimulation by PMA. We can only speculate on the functional significance of CD44 shedding from epithelial cells such as TEC. Shedding has been described for various receptors involved in the regulation of the immune system, including adhesion molecules and cytokine receptors. A general function of shedding is the inhibition of interaction between receptor and ligand. Katoh et al. have shown that soluble CD44 blocks binding of HA to cell bound CD44 [18]. It is possible that shedding of CD44 from TEC could also regulate the interaction of TEC with HA, thereby modulating cell growth and other processes such as cell differentiation.

The ability of CD44 to bind its natural ligand HA differs among cell lines. Three functional states can be distinguished with respect to HA binding: (i) nonbinding; (ii) non-binding but inducible; and (iii) constitutively binding [2]. Monoclonal antibodies against CD44 can be used to modulate the binding for HA in various cells, presumably through changes in conformation of the CD44 molecule. The KM81 mAb for example blocks the binding of HA to CD44, whereas the IRAWB14.4 mAb induces strong HA binding [5,7]. MCT cells belong to the group of cells which bind HA constitutively. We found that the HA binding capacity could also be blocked with KM81 and stimulated with IRAWB14.4 in MCT cells. Although little is known 
regarding the physiological stimuli that modulate HA binding on TEC and other cell types it is possible that biologically relevant stimuli such as growth factors or cytokines also influence the binding of HA.

Using MCT cells as a model system we found that soluble and plate-bound HA inhibit the growth of MCT cells. The role of CD44 and its ligand HA on cell growth has been investigated in several cell types of haematopoietic and non-haematopoietic origin and the relationship is complex. CD44 functions as a costimulatory molecule on T cells $[13,19]$ but can also have a negative influence on T cell proliferation [20]. HA may either stimulate or inhibit endothelial cell and vascular smooth muscle cell proliferation, depending on the concentration and molecular weight of HA [21-24].

Our data suggest that CD44 could inhibit cell growth when interacting with its ligand $\mathrm{HA}$ on TEC. Dissociated proliferating cell nuclear antigen (PCNA) and CD44 expression in epithelial cells of colorectal neoplasms [25], or the progressive loss of CD44 gene expression in invasive bladder cancer [26] are other examples where epithelial CD44 seems to operate as an anti-proliferative molecule. We speculate that CD44 also has a growth inhibitory role on TEC in vivo. By limiting the regeneration rate of injured tubules CD44 could participate in the redifferentiation process in various settings of renal injury. Overshooting of tubular epithelial proliferation after injury could thereby be prevented.

In summary we have shown that MCT cells constitutively express the standard form of CD44 which is shed from the cell surface upon crosslinking of CD44 or after stimulation with PMA. CD44 functions as a receptor for HA on MCT cells and the binding capacity of CD44 for HA can be modulated by different antiCD44 mAbs. The interaction of HA with its receptors significantly inhibits the proliferation of MCT cells by a mechanism which probably involves the CD44 protein. Since CD44 is expressed by injured proximal tubular epithelial cells we postulate that the interaction of HA with CD44 could regulate tubular epithelial cell growth and differentiation in vivo.

Acknowledgements. We thank Dr E. Niederer for helping with flow cytometry, Dr M. Höchli for help with the confocal microscopy, $\mathrm{Mr}$ C. Gasser for the graphic illustrations and M. Pfister for helpful discussions. This study was supported by the Swiss National Science Foundation (grant No. 32-40390.94 to R. P. W.), the OlgaMayenfisch Foundation and the Hartmann-Müller Foundation. B. O. is the recipient of a Postgraduate Fellowship from the University of Zürich and is supported by the Swiss National Science Foundation and the Maurice E. Müller Foundation. XF is the recipient of a Scholarship from the Swiss government. R. P. W. is the recipient of a SCORE A Physician Scientist Award from the Swiss National Science Foundation.

\section{References}

1. Aruffo A, Stamenkovic I, Melnick M, Underhill CB, Seed B. CD44 is the principal cell surface receptor for hyaluronate. Cell 1990; 61: 1303-1313

2. Lesley J, Hyman R, Kincade PW. CD44 and its interaction with extracellular matrix. Adv Immunol 1993; 54: 271-335

3. Benz PS, Fan XH, Wüthrich RP. Enhanced tubular epithelial
CD44 expression in MRL-lpr lupus nephritis. Kidney Int 1996; 50: $156-163$

4. Sibalic V, Fan X, Loffing J, Wüthrich RP. Upregulated renal tubular CD44, hyaluronan and osteopontin in $k d k d$ mice with interstitial nephritis. Nephrol Dial Transplant 1997; 12: 1344-1353

5. Lesley J, He Q, Miyake K, Hamann A, Hyman R, Kincade PW. Requirements for hyaluronic acid binding by CD44: a role for the cytoplasmic domain and activation by antibody. $J$ Exp Med 1992; 175: 257-266

6. Trowbridge IS, Lesley J, Schulte R, Hyman R, Trotter J. Biochemical characterization and cellular distribution of a polymorphic, murine cell-surface glycoprotein expressed on lymphoid tissues. Immunogenetics 1982; 15: 299-312

7. Miyake K, Medina KL, Hayashi S, Ono S, Hamaoka T, Kincade PW. Monoclonal antibodies to Pgp-1/CD44 block lymphohemopoiesis in long-term bone marrow cultures. $J$ Exp Med 1990; 171: 477-488

8. Haverty TP, Kelly CJ, Hines WH et al. Characterization of a renal tubular epithelial cell line which secretes the autologous target antigen of autoimmune experimental interstitial nephritis. J Cell Biol 1988; 107: 1359-1368

9. Wuthrich RP. Vascular cell adhesion molecule-1 (VCAM-1) expression in murine lupus nephritis. Kidney Int 1992; 42: 903-914

10. Chirgwin JM, Przybyla AE, MacDonald RJ, Rutter WJ. Isolation of biologically active ribonucleic acid from sources enriched in ribonuclease. Biochemistry 1979; 18: 5294-5299

11. Hirano H, Screaton GR, Bell MV, Jackson DG, Bell JI, Hodes RJ. CD44 isoform expression mediated by alternative splicing: tissue-specific regulation in mice. Int Immunol 1994; 6: 49-59

12. Lesley J, Hyman R. CD44 can be activated to function as an hyaluronic acid receptor in normal murine T cells. Eur J Immunol 1992; 22: 2719-2723

13. Haynes BF, Telen MJ, Hale LP, Denning SM. CD44-a molecule involved in leukocyte adherence and $\mathrm{T}$ cell activation. Immunol Today 1989; 10: 423-428

14. Günthert U. CD44: a multitude of isoforms with diverse functions. Curr Top Microbiol Immunol 1993; 184: 47-63

15. Roy-Chaudhury P, Khong TF, Williams JH, Haites NE, Wu B, Simpson JG, Power DA. CD44 in glomerulonephritis: Expression in human renal biopsies, the Thy 1.1 model, and by cultured mesangial cells. Kidney Int 1996; 50: 272-281

16. Nikolic-Paterson DJ, Jun Z, Tesch GH, Lan HY, Foti R, Atkins RC. De novo CD44 expression by proliferating mesangial cells in rat anti-Thy-1 nephritis. J Am Soc Nephrol 1996; 7: 1006-1014

17. Yu Q, Toole BP. A new alternatively spliced exon between v9 and v10 provides a molecular basis for synthesis of soluble CD44. J Biol Chem 1996; 271: 20 603-20607

18. Katoh S, McCarthy JB, Kincade PW. Characterization of soluble CD44 in the circulation of mice. Levels are affected by immune activity and tumor growth. J Immunol 1994; 153: 3440-3449

19. Huet S, Groux H, Caillou B, Valentin H, Prieur M, Bernard A. CD44 contributes to T cell activation. J Immunol 1989; 143: 798-801

20. Rothman BL, Blue ML, Kelley KA, Wunderlich D, Mierz DV, Aune TM. Human T cell activation by OKT3 is inhibited by a monoclonal antibody to CD44. J Immunol 1991; 147: 2493-2499

21. West DC, Hampson IN, Arnold F, Kumar S. Angiogenesis induced by degradation products of hyaluronic acid. Science 1985; 228: 1324-1326

22. Kumar S, West DC. The effect of hyaluronate and its oligosaccharides on endothelial cell proliferation and monolayer integrity. Exp Cell Res 1989; 183: 179-196

23. Jain M, He Q, Lee WS, Kashiki S, Foster LC, Tsai JC, Lee ME, Haber E. Role of CD44 in the reaction of vascular smooth muscle cells to arterial wall injury. J Clin Invest 1996; 97: 596-603

24. Papakonstantinou E, Karakiulakis G, Roth M, Block LH. Platelet-derived growth factor stimulates the secretion of hyaluronic acid by proliferating human vascular smooth muscle cells. Proc Natl Acad Sci US A 1995; 92: 9881-9885 
25. Furuta K, Zahurak M, Yang XL, Rosada C, Goodman SN, August JT, Hamilton SR. Relationship between CD44 expression and cell proliferation in epithelium and stroma of colorectal neoplasms. Am J Pathol 1996; 149: 1147-1155

26. Sugino T, Gorham H, Yoshida K, Bolodeoku J, Nargund V, Cranston D, Goodison S, Tarin D. Progressive loss of CD44 gene expression in invasive bladder cancer. Am J Pathol 1996; 149: $873-882$

27. Jun Z, Hill PA, Lan HY, Foti R, Mu W, Atkins RC, NikolicPaterson DJ. CD44 and hyaluronan expression in the develop- ment of experimental crescentic glomerulonephritis. Clin Exp Immunol 1997; 108: 69-77

28. Neame SJ, Isacke CM. Phosphorylation of CD44 in vivo requires both Ser323 and Ser325, but does not regulate membrane localization or cytoskeletal interaction in epithelial cells. $E M B O$ $J$ 1992; 11: 4733-4738

29. Wüthrich RP, Glimcher LH, Yui MA, Jevnikar AM, Dumas SE, Kelley VE. MHC class II, antigen presentation and tumor necrosis factor in renal tubular epithelial cells. Kidney Int 1990; 37: 783-792 